\title{
Experimental study on lowering oleic acid value and peroxide value of camellia sinensis by scraping film molecular distillation
}

\author{
Haodong Zhang ${ }^{1}$, Liu Bin ${ }^{1}$, Longlong Lin², Rongxian $\mathrm{Qu}^{2}$, Chen Wang ${ }^{1}$, Junmei Zhang, \\ ${ }^{1}$ College of Electromechanical Engineering, Qingdao University of Science and Technology, Qingdao 266061, China \\ ${ }^{2}$ Shandong Xinhua Pharmaceutical Company Limited, Zibo 255000, Shandong Province, China \\ ${ }^{3}$ College of Chemical Engineering, Qingdao University of Science and Technology, Qingdao 266042, China
}

\begin{abstract}
Camellia oil is a kind of natural product with high added value. In the process of production, processing, and transportation, acidic substances and peroxides that reduce the quality of oil are produced. In this paper, it was refined by scraping membrane molecular distillation device. The factors affecting the molecular distillation results were analyzed and studied through a single factor experiment and orthogonal experiment. On the surface of the experiment, the optimal process parameters were as follows: the temperature was $190^{\circ} \mathrm{C}$, the pressure was $1 \mathrm{~Pa}$, the scraping speed was $300 \mathrm{r} / \mathrm{min}$, and the feed amount was $900 \mathrm{~g} / \mathrm{h}$. Under this condition, the acid value in camellia oil decreased from $2.67 \mathrm{mgKOH} / \mathrm{g}$ to $0.19 \mathrm{mgKOH} / \mathrm{g}$, and the free fatty acid removal rate was $92.88 \%$. The peroxide value decreased from $16.78 \mathrm{mmol} / \mathrm{kg}$ to $1.03 \mathrm{mmol} / \mathrm{kg}$, and the peroxide removal rate was $93.86 \%$. The experimental results showed that the surface of the scraping membrane molecular distillation equipment could meet the national standard of acid value and peroxide value under the appropriate technological parameters, and there was no solvent residue, which was a safe physical purification process.
\end{abstract}

\section{Introduction}

Scraping film molecular distillation is used to separate materials according to the difference of molecular activity coefficient of different components under the nonequilibrium state of mixture under high vacuum conditions. Under scraper rotor rotation, the material form a thin and uniform on the surface of the evaporation of liquid membrane, and the materials are heated to boiling point. Relying on the theory of molecular thermal motion, the molecular thermal motion of different free paths is intensified under this condition, so that the light molecules escape from the liquid surface of the raw material and condense on the condensation surface, thus completing the separation process of light and light components[1-3]. Scraping membrane molecular distillation technology protects the material activity of original materials on the premise of ensuring polar loss of materials [4-5].

Camellia oil is extracted and pressed from the seeds of the camellia tree, a unique edible oil in south China. As a precious oil with high added value, camellia oil has high medicinal and edible value. It is used in the production of luxury products such as health care products and cosmetics [6-8]. However, the free fatty acids contained in camellia oil can degrade the quality of camellia oil and make it difficult to store. Too long storage time of camellia oil will increase the peroxide content in camellia oil, aggravating the degree of rancidity. To improve the quality of camellia oil, make full use of the resources of camellia oil, based on experiment and purifying of camellia oil, this paper discusses using the blown film type of molecular distillation technology of camellia oil purity to increase at the same time reduce generated during the production of free fatty acid content, with the most gentle way to reduce the damage to the original oil natural ingredients.

\section{Experimental and Results}

\subsection{Materials and instrument}

The raw camellia oil was provided by Guangdong Kangdi Green Biotechnology Co Ltd (Guangzhou, China). The acid and peroxide value is $2.67 \mathrm{mgKOH} / \mathrm{g}$ and 16.78 $\mathrm{mmol} / \mathrm{kg}$, and the boiling point is $230{ }^{\circ} \mathrm{C}$. Other test reagents are $0.1 \mathrm{~mol} / \mathrm{L} \mathrm{KOH}$ and $0.01 \mathrm{~mol} / \mathrm{L} \mathrm{Na}_{2} \mathrm{~S}_{2} \mathrm{O}_{3}$ standard solution, $1 \%$ phenolphthalein indicator, petroleum ether, $95 \%$ ethanol, $30 \mathrm{ml}$ mixture of chloroform and glacial acetic acid (volume ratio 2:3) and $1 \mathrm{ml} \mathrm{KI} \mathrm{saturated} \mathrm{solution} \mathrm{were} \mathrm{provided} \mathrm{by} \mathrm{Guangzhou}$ Chemical Regent Co, Ltd., China.

The experiment equipment which is shown in Fig. 1 is a VKL70-5FDRR type short-path distillation device of full-heating full-gear pump produced by VTA. 


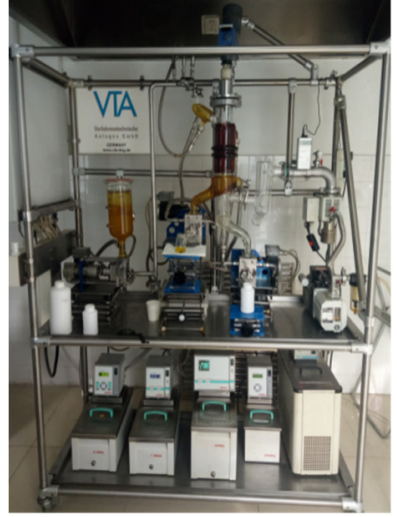

Fig. 1. The equipment of short-path distillation

\subsection{The influence of the scraper speed}

When the speed of the film scraper varied from $150 \mathrm{r} / \mathrm{min}$ to $400 \mathrm{r} / \mathrm{min}$, the influence of film scraping speed on the acid and peroxide value is shown in Fig.2. When the speed of the scraper decreased, the rate of liquid film renewal decreased, resulting in the decrease of the evaporation rate of light components, which was not conducive to the distillation of free acid. With the increase of rotation speed and turbulent energy, the liquid film became thinner; heat and mass transfer accelerated; the removal of light components increased; the corresponding acid and peroxide values also decreased, so the best speed range was $300 \mathrm{r} / \mathrm{min}$ to $325 \mathrm{r} / \mathrm{min}$.

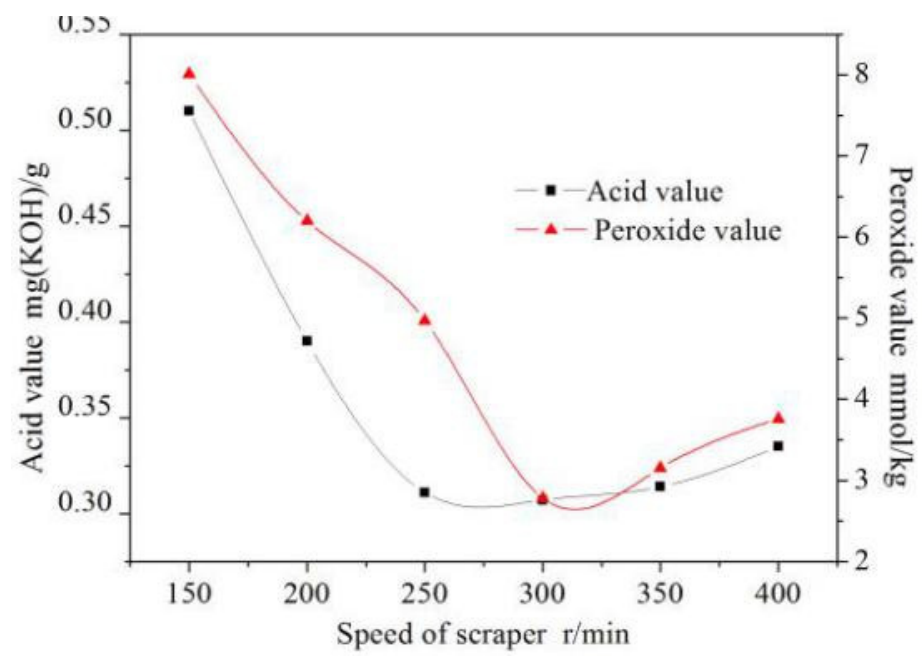

Fig. 2. Variation curves of acid and peroxide value with the scraper speed

\subsection{The effect of the feed speed}

As shown in Fig.3, when the feed speed increased from 500 $\mathrm{g} / \mathrm{h}$ to $1000 \mathrm{~g} / \mathrm{h}$, both of the acid value and peroxide value were on the rise. With the increase of feed speed, the acid value and peroxide value were increased. The more light components did not reach the separation condition, the thicker and shorter the liquid film and residence time became. The rate of feed was supposed to $900 \mathrm{~g} / \mathrm{h}$ by taking the factors into account, such as light component yield, quality, and treatment volume.

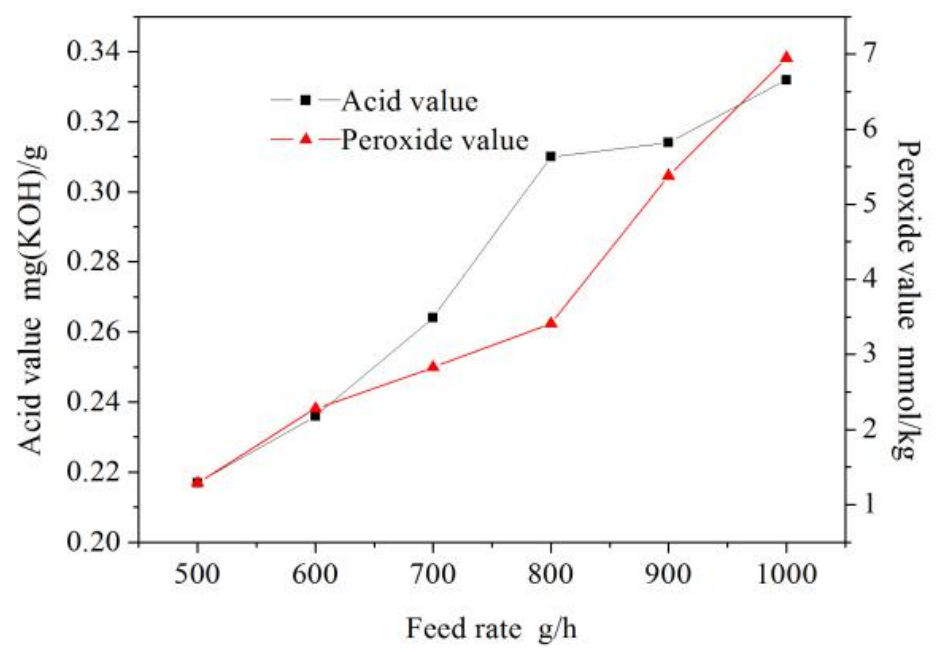

Fig.3. Variation curves of acid and peroxide value with the feed speed

\subsection{The influence of temperature}

The boiling point of camellia oil is $230^{\circ} \mathrm{C}$. The higher temperature can not only destroy the effective components of camellia oil [9-10], but also cause the evaporation of the heavy components. In a certain range, the higher the evaporation surface temperature is, the higher the distillation efficiency is. 


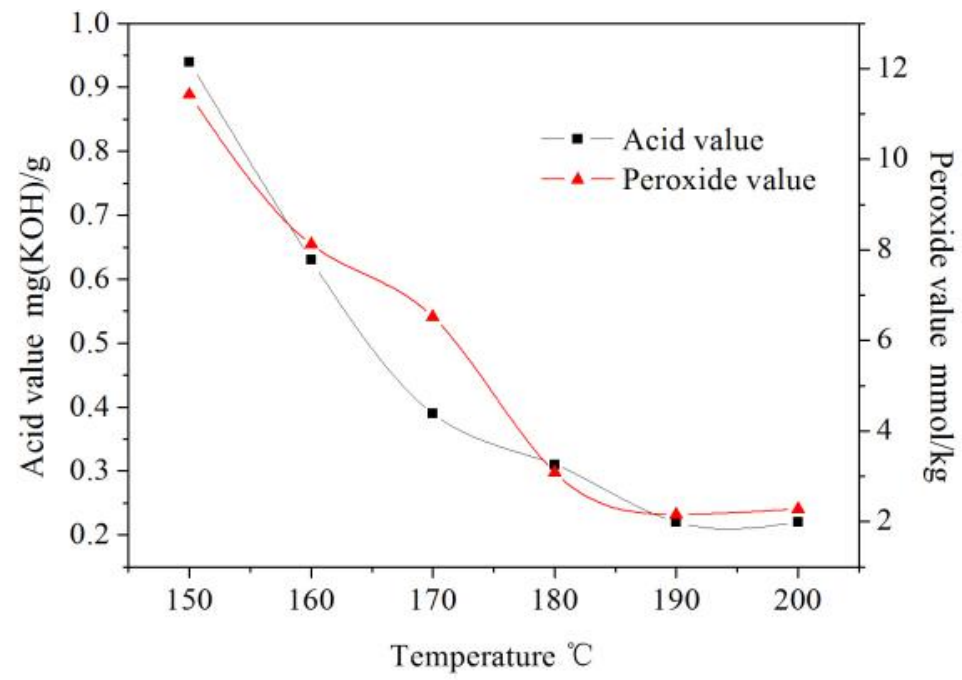

Fig.4. Change of acid valence and peroxide value with temperature

The change of the acid value and peroxide value with the temperature of evaporation is shown in Fig.4. As the temperature rose from $150^{\circ} \mathrm{C}$ to $200^{\circ} \mathrm{C}$, the acid and peroxide value dropped, and they fell most rapidly at the range of $150^{\circ} \mathrm{C}$ to $180^{\circ} \mathrm{C}$. When the temperature arrived at $190^{\circ} \mathrm{C}$, the change of acid and peroxide value were not pronounced and trended to be stable, And the active ingredients in camellia oil can be protected from being destroyed.

\subsection{The effect of pressure}

The lower the system vacuum is, the higher separation efficiency will be obtained. But the lower the vacuum degree is, the more energy will be consumed. At low pressure, light molecules did less work overcoming molecular forces in the liquid membrane, so the possibility of escape of light components was greatly increased. Besides, from the perspective of molecular dynamics, the mean free path of molecules increases as the pressure decreases. The initial kinetic energy was large, so the average free path of movement increased, which make it quickly reach the condensation surface [11].

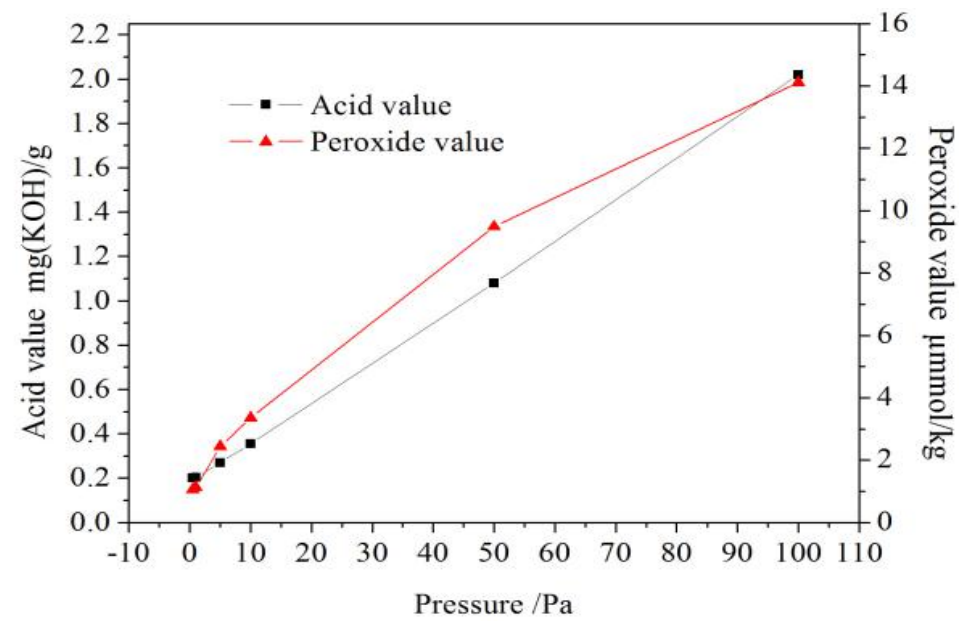

Fig.5. Curves of acid valence and peroxide value with pressure

The condition of pressure was changed, and the other conditions remained the same. It is shown in Fig. 5 that the acid and peroxide values dropped rapidly with the pressure declined. When the pressure was $100 \mathrm{~Pa}$, the acid value was $2.02 \mathrm{mgKOH} / \mathrm{g}$, and the peroxide value was $14.11 \mathrm{mmol} / \mathrm{kg}$, which had a not obvious downward trend compared with the raw oil. When the system pressure dropped to $1.0 \mathrm{~Pa}$, the acid value was $0.203 \mathrm{mgKOH} / \mathrm{g}$, and the peroxide value was $1.13 \mathrm{mmol} / \mathrm{kg}$, which could reach the requirements.

\section{Conclusion}

The experimental data and the quality requirements of the product are analyzed, and the factors of energy consumption are considered. When the process parameters are $190{ }^{\circ} \mathrm{C}, 1.0 \mathrm{~Pa}, 300 \mathrm{r} / \mathrm{min}$, and $900 \mathrm{~g} / \mathrm{h}$, the acid value will decrease from 2.67 to $0.19 \mathrm{mg} \mathrm{KOH} / \mathrm{g}$, which reduces $92.88 \%$, and the peroxide value decreases from $16.78 \mathrm{mmol} / \mathrm{kg}$ to $1.03 \mathrm{mmol} / \mathrm{kg}$, which reduces $93.86 \%$. Compared with the traditional camellia oil refining process (pressing method and leaching method), short-path distillation has greatly improved the oil yield of tea seeds without going through the steps of 
degumming, deacidification, decolorization, fractionation, and deodorization. There are no organic solvents and other chemical residues in the distillate, which protects the ingredients of camellia oil to the greatest extent and the quality of camellia oil can be effectively improved.

\section{References}

1. Ting Xu, Wei Han. The principle and application of molecular distillation[J]. Mechanical and Electrical Information, 2015(08): 1-8.

2. Hongling Dong, Runze Wang. Application of molecular distillation in oil industry[J]. Chemical Design Communication, 2019, 45(03): 55.

3. Xinxin Sun. The research progress of molecular distillation in many fields[J]. Technology and Development of Chemical Industry. 2018, 47(12): 35$37+60$.

4. Zhenya Duan, Maorui Liu, Shaopu Li . Advances in theoretical research on scraping membrane molecular distillation[J] . CHEMICAL ENGINEERING，2017, (9): 13-17.

5. Li L, Liu D C, Wan H L, et al. Removal of chloride impurities from titanium sponge by vacuum distillation[J]. Vacuum, 2018, 152: 166-172.

6. Li Li, Xuehui Wu, Qiaohua Kou .Research status and application prospect of camellia oil[J] . China Oils and Fats, 2010, 35 (3): 10-13 .

7. Yarui Song. Study on the quality and antioxidant properties of Selenium-rich camellia oil[D] .Changsha: Central South University of Forestry and Technology, 2014.

8. Chen Wang . Experimental study on scraping film molecular distillation of camellia oil and simulation of liquid film flow and heat transfer[D]. Qingdao: Qingdao University of Science and Technology, 2019.

9. Salem, M. S., El-shazly, A. H., Nady, N., Elmarghany, M. R., Shouman, M. A., \& Sabry, M. N. (2019). 3-D numerical investigation on commercial PTFE membranes for membrane distillation: Effect of inlet conditions on heat and mass transfer. Case Studies in Thermal Engineering, 100396.

10. Cheng, X. X., Yang, T., Wang, Y. H., Zhou, B. Q., Yan, L., Teng, L. Z., et al. (2018). New method for effective identification of adulterated camellia oil basing on camellia oleifera - specific DNA. Arabian Journal of Chemistry, 11(6), 815-826.

11. Lutišan, J., \& Cvengroš, J. (1995). Mean free path of molecules on molecular distillation. The Chemical Engineering Journal and the Biochemical Engineering Journal, 56(2), 39-50. 